\title{
Bloodstream Infections caused by Klebsiella pneumoniae and Serratia marcescens isolates co-harboring NDM-1 and KPC-2.
}

Taniela Bes ( $\sim$ taniela.bes@hms.harvard.edu )

University of Sao Paulo

Debora Nagano

Universidade de Sao Paulo

Roberta Martins

Universidade de Sao Paulo

Ana Paula Marchi

Universidade de Sao Paulo

Lauro Perdigão Neto

Universidade de Sao Paulo

Hermes Higashino

Universidade de Sao Paulo

Gladys Prado

Universidade de Sao Paulo

Thais Guimaraes

Universidade de Sao Paulo

Anna S Levin

Universidade de Sao Paulo

Silvia Costa

Universidade de Sao Paulo

\section{Short report}

Keywords: Enterobacteriaceae, Carbapenem-resistant, blaKPC-2, blaNDM-1, co-harboring

Posted Date: June 26th, 2020

DOI: https://doi.org/10.21203/rs.2.22113/v2

License: @ (i) This work is licensed under a Creative Commons Attribution 4.0 International License. Read Full License

Version of Record: A version of this preprint was published at Annals of Clinical Microbiology and Antimicrobials on August 30th, 2021. See the published version at https://doi.org/10.1186/s12941-021-00464-5. 


\section{Abstract}

Carbapenem-resistant Enterobacteriaceae is a worldwide health problem, however isolates carrying both blaKPC-2 and blaNDM-1 are unusual. Here we describe microbiological and clinical characteristics of five cases of bloodstream infection (BSI) caused by carbapenem-resistant K/ebsiella pneumoniae and Serratia marcescens co-harboring blaKPC-2 and blaNDM-1.Of the five blood culture isolates, three from are from hematopoietic stem cell transplantation patients, one from a renal transplant patient, and one from a soft tissue surgical patient. All patients lived in low-income neighborhoods and had no travel history. Despite antibiotic treatment, four of five patients died. The phenotypic assays showed that Meropenem added with either EDTA, PA or both showed increased zone of inhibition in comparison to Meropenem alone. Molecular tests confirmed blaKPC-2 and blaNDM- 1 genes, the $K$. pneumoniae were assigned as ST258 and ST340 by Whole Genome Sequencing.

This case-series showed high mortality of BSI caused by Enterobacteria coproducing KPC-2 and NDM-1. The detection of samples co-harboring blaKPC-2 and blaNDM-1 remains unsatisfactory with phenotypic assay. Routine microbiology laboratories must be on alert for samples co-harboring these mechanisms.

\section{Introduction}

In the last decade, several studies have been reported the emergence of Gram-negative bacteria carrying multiple carbapenemases [1-6], isolated from patients with distinct body sites of infection. However, clinical isolates harbouring simultaneously blaKPC-2 and blaNDM-1 are less common. Previous reports describing blaKPC-2 and blaNDM-1 co-production includes clinical isolates of Klebsiella pneumonia [7-9], Klebsiella oxytoca [10], Enterpbacter cloacae [11,12] and Enterobacter hormaechei [13], collected from rectal swab, blood samples, urinary tract infections and wound infections as well. Regarding Serratia marcescens, clinical isolates harbouring simultaneously KPC-2 and IMP-10 [14] or KPC-2 and SRT-2 [15] were described.

The production of carbapenemases, such as Klebsiella pneumoniae carbapenemase (KPC) and New Delhi metallo- $\beta$-lactamase (NDM) constitutes one of the most important mechanisms of resistance to $\beta$-lactam antibiotics [16]. As the emergence of carbapenem-resistant clinical isolates has turned a serious clinical challenge due to the limited treatment options, the co-existence of multiple carbapenemases further aggravates this issue. Concerning Brazilian data, NDM producers were originally detected in the southern regions of Brazil and have since moved into other states. Agents producing KPC alone are the mainly cause of bloodstream infection (BSI) in intensive care unit patients (21\%) in the state of São Paulo, regarding the survilance data [17]. Reports from Brazil also indicate that NDM and KP producers have displayed characteristics such as co-resistance and heteroresistance[12,13,18]. The present study describes the clinical and microbiological features of five cases of Gram-negative bacteria, namely Klebsiella pneumoniae $(\mathrm{n}=4)$ and Serratia marcescens ( $\mathrm{n}=1$ ), coharboring KPC-2 and NDM-1, collected from bloodstream infections (BSI).

\section{Results}

The five clinical isolates analyzed in the present study were collected from BSI of five patients submitted to hematopoietic stem cell transplant ( $\mathrm{n}=3$ ), renal transplant $(n=1)$ and soft tissue surgery $(n=1)$. Regarding socioeconomic features, all patients lived in low-income neighborhoods in São Paulo, have less than eight years of schooling and have no history of international travel.

Three of the four patients infected with $K$. pneumoniae died within the course of the treatment, two of them deceased two days after the diagnosis, and the other patient died 40 days post-BSI culture positive. The patient infected with $S$. marcescens died 11 days after the diagnostic. Patients infected with $K$. pneumoniae $(n=4)$ were treated with meropenem, tigecycline and colistin; the patient infected with S. marcescens received tigecycline and fosfomycin. Clinical data is shown in the table 1.

Microdilution susceptibility test by Sensititre demonstrated resistance to Aztreonam and at leat one more to $\beta$-lactams by all isolates (Table 1). Phenotypic tests revealed probable presence of serine carbapenemase and metallo-beta-lactamase as well. Meropenem added with either Ethylenediaminetetraacetic acid (EDTA), phenylboronic acid (PBA) or both showed increased zone of inhibition in comparison to Meropenem alone.

The isolates (KP1411, KP4301 and KP4990) had full growth around the meropenem disk and, when either EDTA and/or PBA is added to meropenem disk, a inhibition zone higher than $9 \mathrm{~mm}$ was obtained. The remaining two isolates, the $S$. marcescens (SM1581) and KP 1581 did not show a difference higher than $4 \mathrm{~mm}$ in the zone of inhibition in neither combination (Table1).

The PCR analysis detected $b / a_{\mathrm{KPC}-2}$ and $b / a_{\mathrm{NDM}-1}$ genes in all five strains, which were assigned as sequence types (ST) ST340 for the samples KP1411, KP4301 and KP1581 and ST258 for KP4990, using primers previously described by Bradford et al, 2004 and Chen et al, 2011. The PCR result was confirmed by Sanger Sequencing using MegaBACE 1000 (ABI 3730 DNA Analyzer; Applied Biosystems, Alameda, CA). Virulence genes related with adhesion, efflux pump, iron acquisition, regulation and secretion system were present in the four K. pneumoniae samples (Table 1).

\section{Discussion}

To the best of our knowledge, this is the first report describing K. pneumonia and S. marcescens clinical isolates co-harboring blaKPC and blaNDM-1, including K. pneumonia ST258 and ST340, which were not previously described.

The ST258 emerged during the early 2000s as a hybrid clone created by recombination between ST11, ST442 and the ST340, which is a single-locus variant of ST11 as well [19]. These isolates tend to be pan-resistant, restricting the therapeutic options, particularly to high resistant $S$. marcescens isolates, since they are intrinsic resistance to polymyxins [20].

The dissemination of NDM-1 and KPC-2 in Brazil is of great concern since a Providencia rettgeri isolate carrying NDM-1 was described in the South region in 2013 [18] and, subsequently, Rozales et al, 2014 [21], published a study analyzing 1134 isolates of Enterobacteriaceae, among which 11 isolates (0.97\%) harbored blaNDM-1. Noteworthy, none of these cases had a history of traveling outside Brazil, which suggest a local acquisition. The isolates analysed in the 
present study were collected from patients who fulfill the risk factors contributing to infection by co-resistant agents, e.g. low socioeconomic class, low educacional backgroung, severe clinical conditions and poor functional status [8,21,22]. Even outside of the hospital setting there are concerns about KPC-2 producing K. pneumoniae isolates (ST340), as demonstrated by the presence of such samples on the waters of urban rives in Sao Paulo, Brazil [23]. Such a finding has as one possible explanation the inproper treatment of hospital sewage being discarded on the rivers.

Outside the hospital setting, another concern is the lack of basic sanitation. Under this circumstance, Klebsiella pneumoniae isolates (ST340) harbouring KPC2 has been reported in urban areas, in the city of Sao Paulo, Brazil, during a local surveillance study (15).

Our isolates displaye a high-level of resistance to $\beta$-lactams, aminoglycosides, and fluoroquinolones. A possible reason for these results is that carbapenemresistant enterobacteria isolates carrying $b / a_{\mathrm{NDM}-1}$ are more likely to be resistant to several antibiotics. They are often accompanied by other genes, which are resistant to $\beta$-lactams, fluoroquinolones and aminoglycosides [7].

The isolate which was colistin resistant did not harbor plasmidial mediated resistance genes nor chromosomal mutation on the WGS analyzes. We speculate that the resistance derived from virulence genes encoded at Lipopolysaccharide (LPS) rfb locus, wzm and wzt codify the proteins to form an ATP-binding cassette (ABC) transporter responsible for export O-antigenic polysaccharide (O-PS), a glycan necessary to synthetize cell surface LPS. The ABC transporters are formed to a specific 0-PS [24]. The Wzt protein dictates the specificity of the substrate and the glycan chain length, which serves as an export signal recognized by the $\mathrm{ABC}$ transporter. The $K$. pneumoniae isolate 1581 carries just the wzm gene therefore our hypothesis is that lacking wzt trapped the transporter in a state incapable to complete the O-PS export. It might explain the colistin resistance, specifically because in K. pneumoniae the cytosolic glycan synthesis and export are obligatorily coupled [25].

According to table 1, the patient clinical conditions were severe, therefore, the presence of blaKPC-2 and bla NDM-1 might contributed to unfavorable clinical outcome, considering that four of the patients died in this same hospitalization without blood culture clearance. Based on the evidence presented here, significant effort is required to identify these isolates with both resistance genes in the routine and research laboratory. To complicate matters further, we are rising an hypothesis regarding the correlation between high-resistance bacteria found in survilance assays in urban rivers in Sao Paulo, performed by Pereira et al, 2014 and those found in hospitals[23]. The detection of samples co-harboring KPC-2 and NDM-1 remains unsatisfactory with phenotypic tests. As a result, routine microbiology laboratories must be on alert for samples co-harboring these mechanisms. Early detection becomes extremely important for the implementation of infection control measures and epidemiological surveillance, tests as a direct multiplex-PCR from the sample for example would be helpful if performed.

\section{Methods}

Four carbapenem-resistant $K$. pneumoniae and one carbapenem-resistant $S$. marcescens were obtained from blood cultures from patients hospitalized at Hospital das Clínicas, Faculdade de Medicina da Universidade de São Paulo a tertiary teaching hospital in São Paulo, Brazil comprised of 2,200 beds. The isolates belong to the Microbiology Laboratory biobank.

Vitek II (BioMerieux-France) was used to identify the isolates species until February 2015, since then we have been using the Matrix-assisted laser desorption ionization-time of flight (MALD-TOF/Bruker) as well.

The minimum inhibitory concentration (MIC) was tested by Sensititre (ThermoFisher Diagnostics) to Aztreonam, Meropenem, Imipenem, Colistin, Amikacin and Tigecycline [26][27]. The susceptibility test results were interpreted according to the criteria recommended by CLSI M100 (Clinical Laboratory Standards Institute)[28], been considered susceptible if MIC $\leq 1 \mathrm{mg} / \mathrm{mL}$, intermediate if $\mathrm{MIC}=2 \mathrm{mg} / \mathrm{mL}$ and resistant if $\mathrm{MIC} \geq 4 \mathrm{mg} / \mathrm{mL}$ for carbapenems, for example[28]. (Escherichia coli ATCC25922 was used as negative control.

Additional phenotypic analysis was done to characterize the resistance using disk diffusion (DD) method, described by Migliavacca, 2002 [29], using the CLSI cutoffs for carbapenems. Meropenem commercial disks containing 10 $\mu \mathrm{g}$ were added with $0.05 \mathrm{M}$ of Ethylenediaminetetraacetic acid (Sigma-Aldrich, St. 115 Louis, MO) and/or $20 \mathrm{\mu g} \mathrm{ml}^{-1}$ of phenylboronic acid (Sigma-Aldrich, St. Louis, MO). According to Migliavacca et al, 2002 [29], a difference of $\geq 4 \mathrm{~mm}$ in the zone of inhibition diameter was used as criteria to determine whether the isolate produced serine carbapenemase, metallo-beta-lactamase or both in presence of EDTA, PBA or either, respectively, when compared to the MPM disk alone. E. coli ATCC 25922 was used as negative quality control.

To detect carbapenemases genes, we performed PCR using previously described primers for $b / a_{\mathrm{KPC}-2}$ and $b / a_{\mathrm{NDM}-1}$ genes [30-32]. The amplicons were submitted to Sanger Sequencing using MegaBACE 1000 (ABI 3730 DNA Analyser; Applied Biosystems, Alameda, CA) to confirm the gene identity.

Whole Genome Sequencing (WGS) was done by Illumina MiSeq. For the WGS, total DNA was extracted with Illustra bacteria genomicPrep Mini Spin Kit (GE Healthcare Life Sciences). DNA quality was verified using the NanoDrop spectrophotometer (Thermo Scientific, Delaware, USA). The whole genome was sequenced by MiSeq IlluminaTM. Libraries were prepared with the commercial kit Nextera XT IlluminaTM according to manufacturer's instructions. The quality of the files generated in the sequencing was evaluated by FastQC v.0.11.3 and Trimmomatic v.0:33. The genome assembly was performed using Velvet Optimiser v.2.2.5. The genome was annotated with Prokka v.1:11 [33-35]. The ST of the isolates was checked by MLSTfinder tool [36] and confirmed in the database PubMLST (http://pubmlst.org). The gene bla KPC-2 $_{2}$ was manually investigated using Artemis v.16.0.0.

\section{Declarations}

Ethics approval and consent to participate 
The isolates belong to the Microbiology Laboratory biobank and were involved in previous studies, when informed consent term was obtained. This is a retrospective study and all methods were performed in accordance with the guidelines and regulations, approved by the Ethics Committee of Hospital das Clinicas of University of São Paulo, Brazil (approval reference numbers 1.310.231, 2.158.859 and 2.452.282).

\section{Consent for publication}

As the previous item.

\section{Availability of data and materials}

These isolates are placed at GeneBank under the numbers:

KP1411 - Klebsiella pneumoniae - QOIJ00000000

KP1581 - Klebsiella pneumoniae - Q0II00000000

KP4301 - Klebsiella pneumoniae - JABBZC000000000

SM1756 - Serratia marcescens - QJPQ00000000

KP4990 - Klebsiella pneumoniae - QOTZ00000000

\section{Competing interests}

The authors certify that they have NO affiliations with or involvement in any organization or entity with any financial interest in the subject matter or materials discussed in this manuscript.

\section{Funding}

No external founding were neded. The study was performed with internal grants from the Medical Investigation laboratory (LIM-49)

\section{Authors' contributions}

Taniela Bes wrote the main manuscript and the genotypic and phenotypic analyses;

Debora Nagano worked phenotypic and genotypic analyzes, as well as with the whole genome sequencing analyzes;

Roberta Martins worked with the whole genome sequencing analyzes;

Ana Paula Marchi worked phenotypic and genotypic analyzes;

Hermes Higashino, Gladys Prado and Thais Guimaraes were the infectious diseases attendants who manage the patient clinically;

Lauro Perdigão Neto, Anna Levin and Silvia Costa were the main reviewers;

All authors reviewed the manuscript

\section{Acknowledgements}

To all thepatients and physichian envolved as well as to the microbiology laboratory team.

\section{References}

1. Solgi H, Badmasti F, Aminzadeh Z, Giske CG, Pourahmad M, Vaziri F, et al. Molecular characterization of intestinal carriage of carbapenem-resistant Enterobacteriaceae among inpatients at two Iranian university hospitals: first report of co-production of bla NDM-7 and bla OXA-48. Eur J Clin Microbiol Infect Dis [Internet]. Eur J Clin Microbiol Infect Dis; 2017 [cited 2020 Jun 17];36:2127-35. Available from: http://www.ncbi.nlm.nih.gov/pubmed/28639165

2. Kilic A, Baysallar M. The First Klebsiella pneumoniae Isolate Co-Producing OXA-48 and NDM-1 in Turkey. Ann Lab Med [Internet]. Korean Society for Laboratory Medicine; 2015 [cited 2020 Jun 17];35:382-3. Available from: http://www.ncbi.nlm.nih.gov/pubmed/25932453

3. Seiffert SN, Marschall J, Perreten V, Carattoli A, Furrer H, Endimiani A. Emergence of Klebsiella pneumoniae co-producing NDM-1, 0XA-48, CTX-M-15, CMY16, QnrA and ArmA in Switzerland. Int J Antimicrob Agents [Internet]. Int J Antimicrob Agents; 2014 [cited 2020 Jun 17];44:260-2. Available from: http://www.ncbi.nlm.nih.gov/pubmed/25123809

4. Xie L, Dou Y, Zhou K, Chen Y, Han L, Guo X, et al. Coexistence of blaOXA-48 and Truncated blaNDM-1 on Different Plasmids in a Klebsiella pneumoniae Isolate in China. Front Microbiol [Internet]. Front Microbiol; 2017 [cited 2020 Jun 17];8:133. Available from: http://www.ncbi.nlm.nih.gov/pubmed/28210248

5. Remya P, Shanthi M, Sekar U. Prevalence and clonal relatedness of NDM and OXA-48-producing Klebsiella pneumoniae in a tertiary care hospital in South India. J Lab Physicians [Internet]. J Lab Physicians; 2019 [cited 2020 Jun 17];11:312-6. Available from: http://www.ncbi.nlm.nih.gov/pubmed/31929696 
6. Miao M, Wen H, Xu P, Niu S, Lv J, Xie X, et al. Genetic Diversity of Carbapenem-Resistant Enterobacteriaceae (CRE) Clinical Isolates From a Tertiary Hospital in Eastern China. Front Microbiol [Internet]. Front Microbiol; 2018 [cited 2020 Jun 17];9:3341. Available from:

http://www.ncbi.nlm.nih.gov/pubmed/30697205

7. Kumarasamy KK, Toleman MA, Walsh TR, Bagaria J, Butt F, Balakrishnan R, et al. Emergence of a new antibiotic resistance mechanism in India, Pakistan, and the UK: A molecular, biological, and epidemiological study. Lancet Infect Dis. 2010;10:597-602.

8. Yan J, Pu S, Jia X, Xu X, Yang S, Shi J, et al. Multidrug resistance mechanisms of Carbapenem resistant Klebsiella pneumoniae strains isolated in Chongqing, China. Ann Lab Med. 2017;37:398-407.

9. Wei D-D, Wan L-G, Liu Y. Draft Genome Sequence of an NDM-1- and KPC-2-Coproducing Hypervirulent Carbapenem-Resistant Klebsiella pneumoniae Strain Isolated from Burn Wound Infections. Genome Announc [Internet]. American Society for Microbiology (ASM); 2018 [cited 2019 Nov 3];6. Available from: http://www.ncbi.nlm.nih.gov/pubmed/29599157

10. Wang J, Yuan M, Chen H, Chen X, Jia Y, Zhu X, et al. First Report of Klebsiella oxytoca Strain Simultaneously Producing NDM-1, IMP-4, and KPC-2 Carbapenemases. Antimicrob Agents Chemother [Internet]. 2017 [cited 2019 Nov 3];61. Available from: http://www.ncbi.nlm.nih.gov/pubmed/28674063

11. Wu W, Feng Y, Carattoli A, Zong Z. Characterization of an Enterobacter cloacae Strain Producing both KPC and NDM Carbapenemases by Whole-Genome Sequencing. Antimicrob Agents Chemother [Internet]. American Society for Microbiology (ASM); 2015 [cited 2020 Jun 17];59:6625-8. Available from: http://www.ncbi.nlm.nih.gov/pubmed/26248381

12. Quiles MG, Rocchetti TT, Fehlberg LC, Kusano EJU, Chebabo A, Pereira RMG, et al. Unusual association of NDM-1 with KPC-2 and armA among Brazilian Enterobacteriaceae isolates. Brazilian J Med Biol Res. 2015;48:174-7.

13. Pereira PS, Borghi M, Albano RM, Lopes JCO, Silveira MC, Marques EA, et al. Coproduction of NDM-1 and KPC-2 in Enterobacter hormaechei from Brazil. Microb Drug Resist. 2015;21:234-6.

14. Silva KE, Cayô R, Carvalhaes CG, Patussi Correia Sacchi F, Rodrigues-Costa F, Ramos Da Silva AC, et al. Coproduction of KPC-2 and IMP-10 in carbapenem-resistant Serratia marcescens isolates from an outbreak in a Brazilian Teaching Hospital. J Clin Microbiol. 2015;53:2324-8.

15. Quezada-Aguiluz M, Lincopan N, Cerdeira L, Fuga B, Silva F, Barrera B, et al. Draft genome sequence of a multidrug-resistant KPC-2 and SRT-2 coproducing Serratia marcescens strain isolated from a hospitalised patient in Chile. J Glob Antimicrob Resist [Internet]. J Glob Antimicrob Resist; 2020 [cited 2020 Jun 17];21:1-2. Available from: http://www.ncbi.nlm.nih.gov/pubmed/32061814

16. Walsh TR, Toleman MA, Poirel L, Nordmann P. Metallo- $\beta$-lactamases: The quiet before the storm? Clin Microbiol Rev. 2005;18:306-25.

17. Centro de Informações Estratégicas em Vigilância em Saúde - CIEVS - SP | Secretaria Municipal da Saúde | Prefeitura da Cidade de São Paulo [Internet]. [cited 2020 Jun 21]. Available from: https://www.prefeitura.sp.gov.br/cidade/secretarias/saude/vigilancia_em_saude/index.php?p=236957

18. Carvalho-Assef APD, Pereira PS, Albano RM, Beriao GC, Chagas TPG, Timm LN, et al. Isolation of NDM-producing Providencia rettgeri in Brazil. J Antimicrob Chemother [Internet]. 2013 [cited 2019 Nov 3];68:2956-7. Available from: http://www.ncbi.nlm.nih.gov/pubmed/23869051

19. Munoz-Price LS, Poirel L, Bonomo RA, Schwaber MJ, Daikos GL, Cormican M, et al. Clinical epidemiology of the global expansion of Klebsiella pneumoniae carbapenemases. Lancet Infect Dis [Internet]. 2013 [cited 2019 Nov 3];13:785-96. Available from:

http://www.ncbi.nlm.nih.gov/pubmed/23969216

20. Kazi M, Shetty A, Rodrigues C. The Carbapenemase Menace: Do Dual Mechanisms Code for More Resistance? Infect Control Hosp Epidemiol [Internet]. 2015 [cited 2019 Nov 3];36:116-7. Available from: http://www.ncbi.nlm.nih.gov/pubmed/25627774

21. Rozales FP, Ribeiro VB, Magagnin CM, Pagano M, Lutz L, Falci DR, et al. Emergence of NDM-1-producing Enterobacteriaceae in Porto Alegre, Brazil. Int J Infect Dis [Internet]. 2014 [cited 2019 Nov 3];25:79-81. Available from: http://www.ncbi.nlm.nih.gov/pubmed/24857802

22. Jia X, Dai W, Ma W, Yan J, He J, Li S, et al. Carbapenem-resistant E. cloacae in Southwest China: Molecular analysis of resistance and risk factors for infections caused by NDM-1-producers. Front Microbiol. 2018;9:1-11.

23. Oliveira S, Moura RA, Silva KC, Pavez M, Mcculloch JA, Dropa M, et al. Isolation of kPC-2-producing Klebsiella pneumoniae strains belonging to the highrisk multiresistant clonal complex 11 (ST437 and ST340) in urban rivers. J Antimicrob Chemother. 2014;69:849-52.

24. Cuthbertson L, Kimber MS, Whitfield C. Substrate binding by a bacterial ABC transporter involved in polysaccharide export. Proc Natl Acad Sci [Internet]. 2007 [cited 2019 Nov 3];104:19529-34. Available from: http://www.ncbi.nlm.nih.gov/pubmed/18032609

25. Davidson AL, Dassa E, Orelle C, Chen J. Structure, Function, and Evolution of Bacterial ATP-Binding Cassette Systems. Microbiol Mol Biol Rev. 2008;72:317-64.

26. Doern G V, Staneck JL, Needham C, Tubert T. Sensititre autoreader for same-day breakpoint broth microdilution susceptibility testing of members of the family Enterobacteriaceae. J Clin Microbiol [Internet]. 1987 [cited 2020 Jun 17];25:1481-5. Available from:

http://www.ncbi.nlm.nih.gov/pubmed/3114321

27. Staneck JL, Allen SD, Harris EE, Tilton RC. Automated reading of MIC microdilution trays containing fluorogenic enzyme substrates with the Sensititre Autoreader. J Clin Microbiol [Internet]. 1985 [cited 2020 Jun 17];22:187-91. Available from: http://www.ncbi.nlm.nih.gov/pubmed/4031033

28. Dolinsky AL. M100 Performance Standards for Antimicrobial Susceptibility Testing [Internet]. J. Serv. Mark. 2017. Available from: http://www.emeraldinsight.com/doi/10.1108/08876049410065598

29. Migliavacca R, Docquier J-D, Mugnaioli C, Amicosante G, Daturi R, Lee K, et al. Simple microdilution test for detection of metallo-beta-lactamase production in Pseudomonas aeruginosa. J Clin Microbiol [Internet]. American Society for Microbiology (ASM); 2002 [cited 2019 Nov 3];40:4388-90. Available from: http://www.ncbi.nlm.nih.gov/pubmed/12409438

30. Rizek C, Fu L, dos Santos LC, Leite G, Ramos J, Rossi F, et al. Characterization of carbapenem-resistant Pseudomonas aeruginosa clinical isolates, carrying multiple genes coding for this antibiotic resistance. Ann Clin Microbiol Antimicrob. 2014;13:4-8.

Page 5/8 
31. Chen Y, Zhou Z, Jiang Y, Yu Y. Emergence of NDM-1-producing Acinetobacter baumannii in China. J Antimicrob Chemother [Internet]. J Antimicrob Chemother; 2011 [cited 2020 Jun 21];66:1255-9. Available from: http://www.ncbi.nlm.nih.gov/pubmed/21398294

32. Bradford PA, Bratu S, Urban C, Visalli M, Mariano N, Landman D, et al. Emergence of carbapenem-resistant Klebsiella species possessing the class A carbapenem-hydrolyzing KPC-2 and inhibitor-resistant TEM-30 beta-lactamases in New York City. Clin Infect Dis [Internet]. Clin Infect Dis; 2004 [cited 2020 Jun 21];39:55-60. Available from: http://www.ncbi.nlm.nih.gov/pubmed/15206053

33. Galens K, Orvis J, Daugherty S, Creasy HH, Angiuoli S, White O, et al. The IGS Standard Operating Procedure for Automated Prokaryotic Annotation. Stand Genomic Sci [Internet]. BioMed Central; 2011 [cited 2020 Jun 17];4:244-51. Available from:

http://www.standardsingenomics.org/index.php/sigen/article/view/sigs.1223234

34. DR Z. Using the Velvet De Novo Assembler for Short-Read Sequencing Technologies. Curr Protoc Bioinforma [Internet]. Curr Protoc Bioinformatics; 2010 [cited 2020 Jun 17];Chapter 11. Available from: https://pubmed.ncbi.nlm.nih.gov/20836074/

35. Zerbino DR, Birney E. Velvet: algorithms for de novo short read assembly using de Bruijn graphs. Genome Res [Internet]. Cold Spring Harbor Laboratory Press; 2008 [cited 2020 Jun 17];18:821-9. Available from: http://www.ncbi.nlm.nih.gov/pubmed/18349386

36. Larsen M V, Cosentino S, Rasmussen S, Friis C, Hasman H, Marvig RL, et al. Multilocus sequence typing of total-genome-sequenced bacteria. J Clin Microbiol [Internet]. J Clin Microbiol; 2012 [cited 2020 Jun 17];50:1355-61. Available from: http://www.ncbi.nlm.nih.gov/pubmed/22238442

\section{Table}

Table 1: Clinical characteristics, outcome, phenotypic analyze, virulence and resistance-associated genes identified by whole genome sequence.

MPM: Meropenem; IMP: Imipenem; ERT: Ertapenem; PBA: Phenylboronic Acid; DD: Difusion Disk. 


\begin{tabular}{|c|c|c|c|c|c|c|}
\hline $\begin{array}{l}\text { Isolate } \\
\text { MLST }\end{array}$ & $\begin{array}{l}\text { Underlying } \\
\text { diseases/Approach }\end{array}$ & $\begin{array}{l}\text { Treatment and } \\
\text { outcome }\end{array}$ & $\begin{array}{l}\text { Phenotypic Tests - serina- } \\
\beta \text {-lactamases (DD mm) }\end{array}$ & $\begin{array}{l}\text { Phenotypic Tests - MBLs } \\
\text { (DD mm) }\end{array}$ & Carbapenembac & $\begin{array}{l}\text { beta } \\
\text { Lact } \\
\text { resis } \\
\text { gent }\end{array}$ \\
\hline $\begin{array}{l}\text { K. pneumoniae } \\
(1411) \\
10 / 19 / 2012 \\
\text { ST340 }\end{array}$ & $\begin{array}{l}\text { Myelodysplastic syndrome } \\
\text { Leukocytes: } 100 \\
\text { Neutrophils: 0 } \\
\text { Allogeneic BMT } \\
(10 / 11 / 2012)\end{array}$ & $\begin{array}{l}\text { Meropenem + } \\
\text { Colistin } \\
\text { Death } 2 \text { days } \\
\text { after blood } \\
\text { culture-positive }\end{array}$ & $\begin{array}{l}\text { DD }(\mathrm{mm}) \\
\text { IMP: } 0 \\
\text { ERT: } 0\end{array}$ & $\begin{array}{l}\text { DD }(\mathrm{mm}) \\
\text { IMP: } 0 \\
\text { ERT: } 0 \\
\text { MPM: } 0\end{array}$ & Positive & $\begin{array}{l}\text { blac } \\
15 \\
\text { blak } \\
\text { blas } \\
11 \\
\text { blaT } \\
1 \mathrm{~B}\end{array}$ \\
\hline
\end{tabular}

$\mathrm{DD}(\mathrm{mm})$ agents

combination:

MPM+PBA: $14 \mathrm{~mm} \quad$ DD $(\mathrm{mm})$ agents

MPM+EDTA+PBA: $17 \mathrm{~mm}$ combination:

MPM+EDTA: 0 (phantom

zone 14)

MPM+EDTA+PBA: $17 \mathrm{~mm}$

\begin{tabular}{|c|c|c|c|c|c|c|}
\hline $\begin{array}{l}\text { K. pneumoniae } \\
\text { (1581) } \\
12 / 14 / 2012 \\
\text { ST340 }\end{array}$ & $\begin{array}{l}\text { Severe aplastic anemia } \\
\quad \text { Leukocytes: } 100 \\
\text { Neutrophils: } 0 \\
\text { Not related allogeneic TCTH } \\
(12 / 09 / 2012)\end{array}$ & $\begin{array}{l}\text { Meropenem + } \\
\text { Colistin } \\
\text { Death } 2 \text { days } \\
\text { after blood } \\
\text { culture-positive }\end{array}$ & $\begin{array}{l}\text { DD }(\mathrm{mm}) \\
\text { IMP: } \\
23 \mathrm{~mm} \\
\text { ERT: } \\
16 \mathrm{~mm} \\
\text { MPM: } 20 \mathrm{~mm}\end{array}$ & $\begin{array}{l}\text { DD }(\mathrm{mm}) \\
\text { IMP: } \\
23 \mathrm{~mm} \\
\text { ERT: } \\
16 \mathrm{~mm} \\
\text { MPM: } 20 \mathrm{~mm}\end{array}$ & Positive & $\begin{array}{l}\text { blak } \\
\text { blaS } \\
11\end{array}$ \\
\hline
\end{tabular}

DD (mm) agents

combination:

MPM+PBA: 23mm

MPM+EDTA+PBA: $23 \mathrm{~mm}$
$\mathrm{DD}(\mathrm{mm})$ agents

combination:

MPM+EDTA: $21 \mathrm{~mm}$

MPM+EDTA+PBA: $23 \mathrm{~mm}$
K. pneumoniae

(4301)

10/16/2014

ST340

Non-Hodgkin lymphoma
Peripheral T-cell
lymphoma Leukocytes:
3,33 Neutrophils: 2,43
Autologous BMT
9/17/2014

Meropenem +

Colistin

Discharge from

hospital 23 days

after blood

culture-positive,

for a total of 64

days

hospitalization

DD (mm)
IMP: 0
ERT: 0
MPM: 0

$\mathrm{DD}(\mathrm{mm})$ agents

combination:

MPM+PBA: $13 \mathrm{~mm}$

MPM+EDTA+PBA: $18 \mathrm{~mm}$

$\begin{array}{lll}\text { DD }(\mathrm{mm}) & \text { Positive } & \text { blak } \\ \text { IMP: } 0 & & \text { blaS } \\ \text { ERT: } 0 & & \text { blaS } \\ \text { MPM: } 0 & \end{array}$

$\mathrm{DD}(\mathrm{mm})$ agents

combination:

MPM+EDTA: 10

(phantom zone 14)

MPM+EDTA+PBA: $18 \mathrm{~mm}$

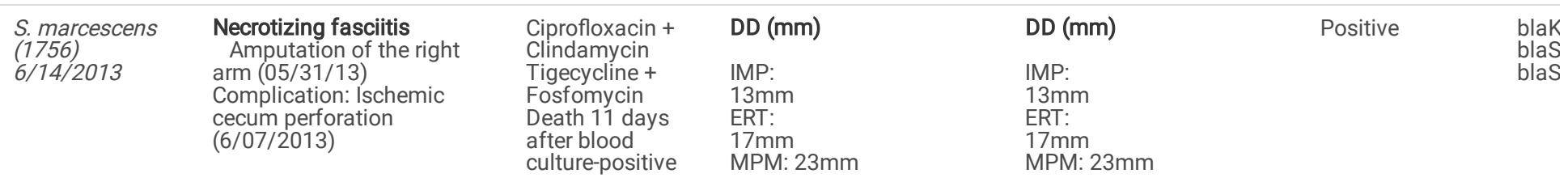

\begin{tabular}{|c|c|c|c|c|c|c|}
\hline & & & $\begin{array}{l}\text { DD }(\mathrm{mm}) \text { agents } \\
\text { combination: } \\
\text { MPM+PBA: } 25 \mathrm{~mm} \\
\text { MPM+EDTA+PBA: } 26 \mathrm{~mm}\end{array}$ & $\begin{array}{l}\text { DD }(\mathrm{mm}) \text { agents } \\
\text { combination: } \\
\text { MPM+EDTA: } 19 \mathrm{~mm} \\
\text { MPM+EDTA+PBA: } 26 \mathrm{~mm}\end{array}$ & & \\
\hline \multirow{2}{*}{$\begin{array}{l}\text { K. pneumoniae } \\
\text { (4990) } \\
10 / 21 / 16 \\
\text { ST258 }\end{array}$} & \multirow{2}{*}{$\begin{array}{l}\text { Kidney transplant due } \\
\text { Chronic Kidney } \\
\text { Disease } \\
(10 / 13 / 16) \quad \text { Urinary } \\
\text { tract infection } \\
(10 / 20 / 16)\end{array}$} & \multirow{2}{*}{$\begin{array}{l}\text { Ceftazidime + } \\
\text { Avibactam } \\
\text { Death } 40 \text { days } \\
\text { after blood } \\
\text { culture-positive }\end{array}$} & $\mathrm{DD}(\mathrm{mm})$ & $\mathrm{DD}(\mathrm{mm})$ & \multirow[t]{2}{*}{ Positive } & \multirow{2}{*}{$\begin{array}{l}\text { blac } \\
14 \\
\text { blak } \\
\text { blas } \\
11\end{array}$} \\
\hline & & & $\begin{array}{l}\text { IMP: } \\
\text { 6mm } \\
\text { ERT: } 0\end{array}$ & $\begin{array}{l}\text { IMP: } 6 \mathrm{~mm} \\
\text { ERT: } \\
0\end{array}$ & & \\
\hline
\end{tabular}


Graft Nephrectomy

$(11 / 23 / 16)$
MPM: 0 (phantom zone

$7 \mathrm{~mm}$ )

$\mathrm{DD}(\mathrm{mm})$ agents

combination:

MPM+PBA: $14 \mathrm{~mm}$

MPM+EDTA+PBA: $16 \mathrm{~mm}$

(phantom zone 20)
MPM: 0 (phantom zone $7 \mathrm{~mm})$

\section{Figures}

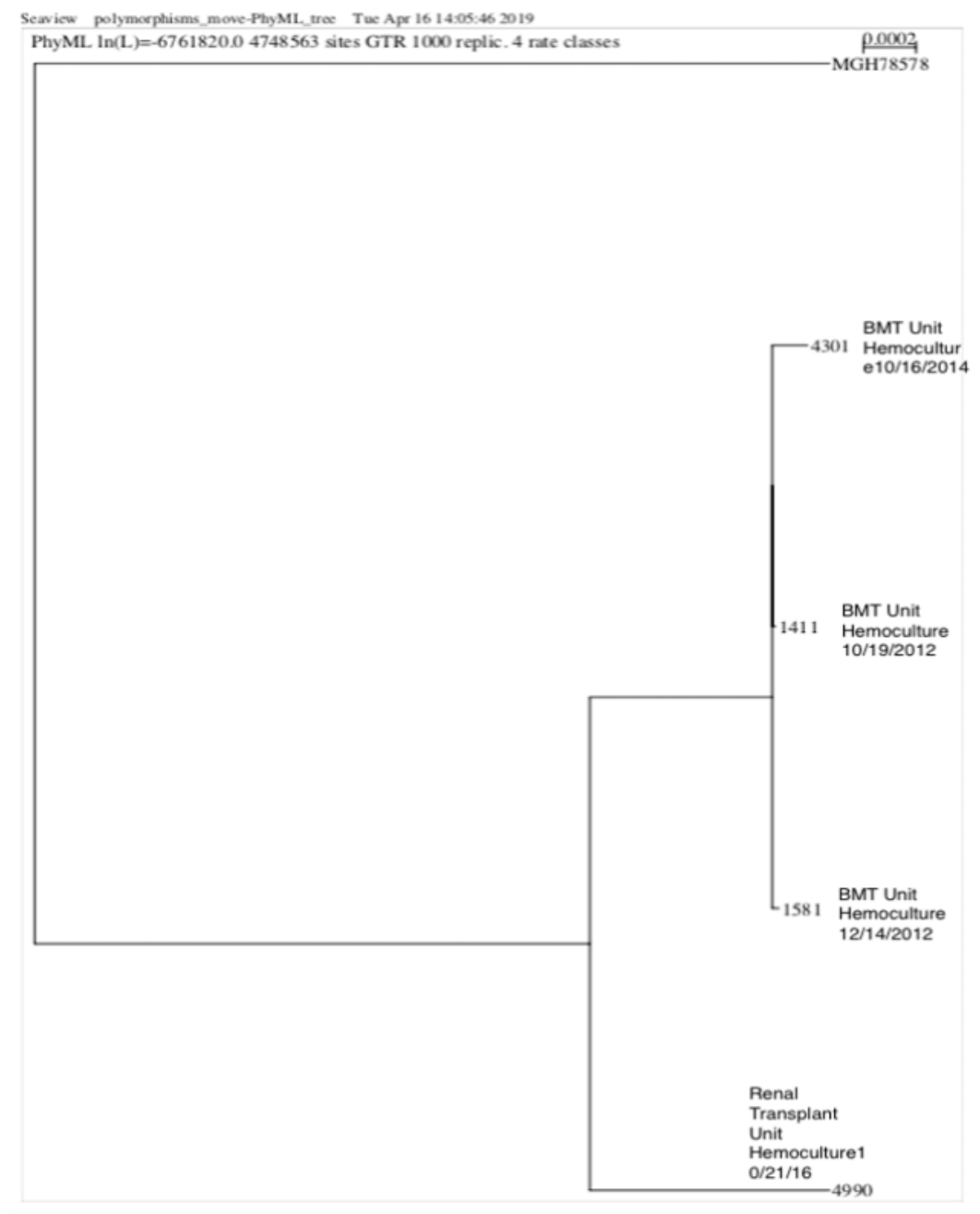

\section{Figure 1}

Phylogenies of K. pneumoniae showing the same clone ST340 in the BMT unit and the globally disseminated, ST258 in Renal Transplant Unit. 